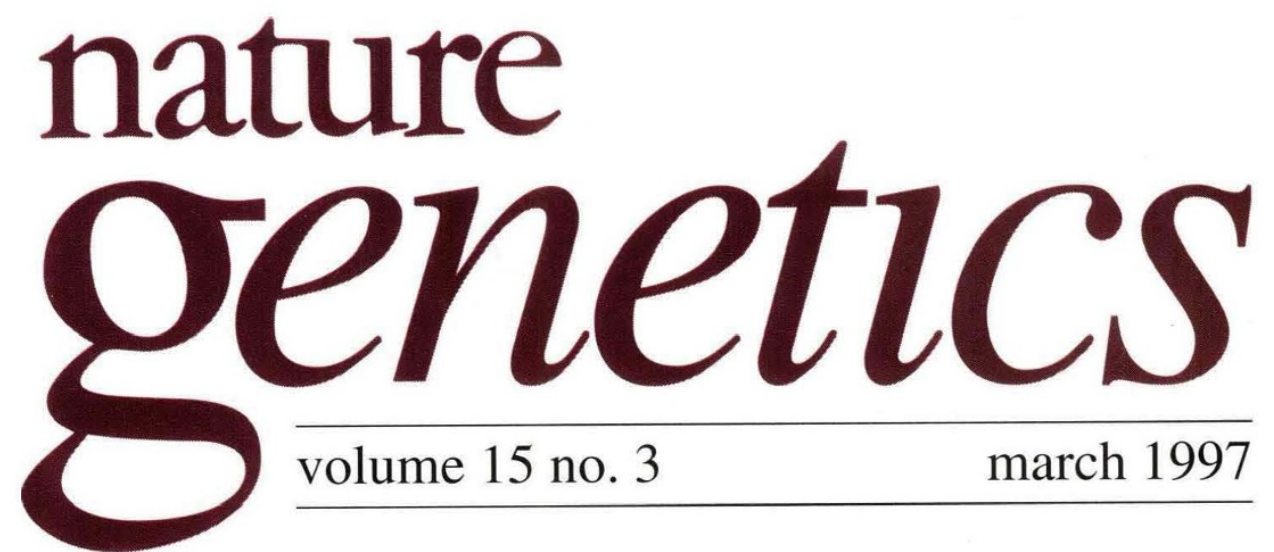

\title{
Cancer wars on all fronts
}

Among the first cases of prostate cancer diagnosed this year was that of legendary golfer Arnold Palmer, who announced at a press conference that he was choosing to have a radical prostatectomy (removal of the prostate gland), despite the wellpublicized, serious risks of incontinence and impotence. Palmer drew an analogy with a golfer who has hit the ball into a bunker, and must decide whether to play safe and chip it onto the fairway, or aim to blast the ball through the trees and onto the green. Like General H. Norman Schwarzkopf before him, Palmer preferred to be rid of the cancer in one fell swoop.

Ten or twenty years ago, it would have been inconceivable that the likes of Palmer and Schwarzkopf would be holding press briefings, posing for the cover of Time or discussing sexual performance on CNN's Larry King Live. Such impressive candour (hardly men's strong suit) has had an enormously positive effect in boosting cancer awareness, explaining in large part the recent surges in the number of new diagnoses of breast and prostate cancer in particular, and in turn increasing the chances of early and successful treatment. For example, the incidence of prostate cancer in the United States has risen 200 per cent since 1990, whereas the number of deaths has increased at less than one fifth of that rate. The

Table Estimated number of new cancer cases and deaths in the US in 1997

\begin{tabular}{lrr}
\hline & Incidence & Deaths \\
Prostate & 334,500 & 41,800 \\
Breast & 181,600 & 44,190 \\
Lung & 178,100 & 160,400 \\
Colon & 94,100 & 46,600 \\
Lymphoma & 61,100 & 25,280 \\
Bladder & 54,500 & 11,700 \\
Melanoma & 40,300 & 7,300 \\
Rectum & 37,100 & 8,300 \\
Kidney & 28,800 & 11,300 \\
Leukaemia & 28,300 & 21,310 \\
Pancreas & 27,600 & 28,100 \\
Ovarian & 26,800 & 14,200 \\
Brain & 17,600 & 13,200 \\
$\quad$ (nervous system) & & \\
\hline
\end{tabular}

Source: Parker, S.L. et al. CA Cancer J. Clin. 47, 5-27 (1997). The figures are based on cancer statistics gathered by the NCl's Surveilance, Epidemiology, and End Results (SEER) Program, and population data collected by the US Bureau of the Census. new enlightenment is also helping to raise millions of dollars for research, as the billionaire Michael Milken has done for his CaP CURE foundation to fight prostate cancer.

Despite this improved dialogue, the latest statistical analysis of cancer trends, carried out by Phyllis Wingo and colleagues ${ }^{1}$ at the American Cancer Society in Atlanta, Georgia, and published in $C A-A$ Cancer Journal for Clinicians, provides a sobering reminder of "the awful burden of cancer," as the National Cancer Institute ( $\mathrm{NCI}$ )'s director Richard Klausner puts it. The report shows that the incidence of many cancers in the United States and elsewhere remains staggeringly high (see Table). Among the 'highlights' of the 1997 analysis are the following:

- Nearly 1.4 million new cases of invasive cancer and another 900,000 skin cancers will be diagnosed this year in the United States. These include 180,000 new cases of breast cancer ( $30 \%$ of cancer cases among women), and over 300,000 new cases of prostate cancer ( $43 \%$ of the total in men). The lifetime risk of cancer for American men is one in two.

- American women have the highest death rate in the world from lung cancer which, as the president of the American Cancer Society, Myles Cunningham, points out in an accompanying guest editorial ${ }^{2}$, represents "a sorry commentary indeed on history's most technologically advanced society." 
- More than 1,500 Americans die each day of cancer - an estimated 560,000 this year. To keep this in perspective, however, that is still 200,000 fewer than will die from heart disease.

- An analysis of age-adjusted cancer death rates shows that, over the past 25 years, the only increase among females is for lung cancer. In males, the sharpest increase is also for lung cancer, with other increases in prostate and pancreatic cancer.

- Variations between different countries illustrate the remarkable differences in death rates for specific cancers, for a variety of environmental reasons. For example, Japan, China, Singapore, Kyrgyzstan, and Trinidad and Tobago have some of the lowest death rates from prostate cancer, but Japan and China rank among the highest for stomach cancer and Singapore for oral cancer. The United States, Cuba and Australia have the lowest death rates from stomach cancer, but the United States boasts the highest death rate in women from lung cancer. The United Kingdom has the highest death rate from breast cancer, but one of the lower rates of uterine cancer.

Overall, there is some heartening news from the 1997 survey. Survival rates in the United States are generally improving - especially for testicular cancer and Hodgkin's disease - although African Americans tend to be diagnosed later than whites and have poorer survival rates for nearly all forms of cancer. Moreover, the death rate from cancer appears to be continuing the slow but steady decline that has been apparent over the past five years or so. Nevertheless, 25 years after President Richard Nixon declared a 'War on Cancer,' the NCI is seeking a budget of almost $\$ 2.3$ billion for 1998. In his budget proposal, Klausner stresses five new funding priorities, including cancer genetics, detection technologies and developmental diagnostics. Leading the attack is a new NCI initiative called the Cancer Genome Anatomy Project (CGAP), the goal of which is to foster collaborations between academic institutions and industry "to achieve the comprehensive molecular characterization of normal, precancerous and malignant cells." One of the first priorities of CGAP is to create a 'tumour gene index' - a catalogue of all genes expressed in tumour cells, focusing initially on breast, colon, lung, ovarian and prostate cancers. cDNA libraries (with special emphasis on full-length cDNAs) constructed from microdissected tissue will provide the template for sequencing projects, with information stored in a new user-friendly database and web page. A second goal is to develop new technologies for expression and mutation analysis of genes (and proteins) on a genome-wide level.

Few readers of this journal will quarrel with the NCI's desire for more research in cancer genetics or encouragement of new technologies to probe the workings of the cancer cell. Recent successes in mapping and/or defining cancer-causing genes give hope that new insights into the molecular basis of these diseases are in the offing. Myriad Genetics and the M.D. Anderson Cancer Center say they have identified a susceptibility gene for brain cancer, data for which should be subjected

1. Parker, S.L., Tong, T., Bolden, S. \& Wingo. P.A. CA Cancer S. Clin. 47, 5-27 (1997). 2. Cunningham, M.P. CA Cancer J. Clin. 47, 34 (1997).

3. Proctor, R.N. The Sciences March/April, 20 24 (1995).

\section{Correction}

In February's editorial the complete citation for the conference should have read: Yeast Genetics and Human Disease, Baltimore, Maryland, November 14-17, 1996. Sponsored by the American Society for Microbiology in collaboration with The Johns Hopkins University. Coorganizers, Philip Hieter \& David Valle (Johns Hopkins University). to peer review without delay. And gene therapy trials for lung and ovarian cancers, among others, are proceeding well.

But in spite of the massive expenditure and promising new technology being applied to cancer research, the most effective countermeasures will probably always lie in prevention. Reducing tobacco use alone might reduce the cancer burden by as much as 30\% (although the US Treasury would doubtless miss the $\$ 13$ billion generated annually by tobacco taxes). The author Robert Proctor put it like this: "Cancer is the product of bad habits, bad government, bad business and bad luck - including the luck of one's genetic draw and the culture into which one is born." ${ }^{3}$ Klausner's budget request concludes, "We are beginning to know this disease." He's right, but as Proctor points out: "Activists who push for 'more research' must ask: What kind of knowledge? Knowledge to what end? As citizens, we all need to appreciate not only how ignorance can invite knowledge but also how knowledge can abide ignorance, despite all our efforts to clear a path from one to the other." 